Diklus: Jurnal Pendidikan Luar Sekolah, 2(1), Maret 2018 - 53

Widya Eka Wahyu Lestari

\title{
EVALUASI PROGRAM KURSUS OFFICE TERPADU DI LEMBAGA KURSUS DAN PELATIHAN (LKP) BIMANTARA KLATEN
}

\section{EVALUATION OF INTEGRATED OFFICE COURSES PROGRAM IN COURSE AND TRAINING AGENCY (LKP) OF BIMANTARA KLATEN}

\author{
Oleh: \\ Widya Eka Wahyu Lestari, Universitas Negeri Yogyakarta \\ widyal531@gmail.com
}

\begin{abstract}
Abstrak
Penelitian ini bertujuan untuk mengetahui keberhasilan program kursus office terpadu di LKP Bimantara. Hasil penelitian menunjukkan bahwa (1) kebermanfaatan program kursus office terpadu adalah melalui hasil evaluasi reaksi: program kursus ofice terpadu diselenggarakan selaras dengan motivasi, harapan, fasilitas yang diberikan dan kualitas pengajar hanya pada kendala ketersediaan ruangan yang terbatas, evaluasi belajar: terjadi perubahan sikap, pengetahuan dan ketrampilan pada peserta pelatihan, serta pembelajaran mengacu pada kurikulum nasional program, hanya evaluasi perilaku: adanya partisipasi peserta pelatihan yang cukup baik sehingga tercapainya tujuan peserta pelatihan, yang perlu diperhatikan dalam pelaksanannya, yaitu pada jadwal pelaksanaan program dan metode pembelajaran untuk menghilangkan kejenuhan,evaluasi hasil: membekali peserta pelatihan dengan ketrampilan menggunakan microsoft office yang nantinya sebagai bekal di dunia kerja, dan peserta pelatihan lebih percaya diri dan yakin dengan kemampuan mereka miliki (2) faktor pendukung yaitu dalam penyelenggaraan programadanya dukungan sarana prasarana yang memadai, serta pembiayaan dari masing-masing peserta pelatihan dan lembaga
\end{abstract}

Kata kunci: Evaluasi, Program Kursus Microsoft Office

\begin{abstract}
This study aims to determine the success of the integrated office course program in LKP Bimantara. The results of the research indicate that (1) the usefulness of the integrated office course program is through the results of the reaction evaluation: the integrated office course program is organized in line with the motivation, expectations, facilities provided and the quality of teachers, and limeted room availability, evaluation of learning: attitude change, knowledge and skills to the trainees, as well as learning refers to the national curriculum of computer programs, behavioral evaluation: the participation of trainees is good enough so that the achievement of the training participants objectives, which need to be considered in the implementation of the program are the program schedule and learning methode to eliminate saturation, evaluation results: equip participants with skills to use Microsoft Office which later as stock in the world of work, and trainees more confident and confident with their ability (2) supporting factors that is in the implementation of the program the existence of adequate infrastructure support, as well as the financing of each trainee and institution
\end{abstract}

Keywords: Evaluation, Microsoft Office Course Program

\section{PENDAHULUAN}

Berbagai upaya yang dilakukan oleh pemerintah dalam meningkatkan potensi sumber daya manusia (SDM) yaitu melalui program pendidikan, baik dalam pendidikan formal maupun nonformal. Saat ini sedang gencar-gencarnya dilakukan oleh pemerintah kabupaten klaten. Kebijakan ini ditempuh setelah melihat kenyataan bahwa $65 \%$ penganggur terdidik adalah lulusan pendidikan menengah, yang dapat diartikan sebagai kurangnya keterampilan lulusan pendidikan menengah untuk masuk lapangan kerja. Peningkatan kualitas sumber daya manusia dapat dilakukan melalui peningkatan mutu pendidikan.

Memasuki era globalisasi persaingan dalam mendapatkan pekerjaan semakin ketat. Tingkat Pengangguran Terbuka (TPT) Jawa 


\section{Diklus: Jurnal Pendidikan Luar Sekolah, 2(1), Maret 2018 - 54 \\ Widya Eka Wahyu Lestari}

Tengah Agustus 2016 sebesar 4,63 persen, mengalami penurunan sebesar 0,36 persen dibanding TPT Agustus 2015 (4,99 persen) dan mengalami peningkatan sebesar 0,43 persen dibandingkan TPT Februari 2016 (4,20 persen). Hasil survei Angkatan Kerja Nasional (Sakernas) menunjukan tingkat penduduk usia kerja semakin meningkat dari tahun ke tahun, pada tahun 2012 sebanyak 879.138 orang, pada tahun 2013 menjadi 887. 039 orang, pada tahun 2014 sebanyak 894.546 orang dan pada tahun 2015 menjadi 902.528 orang. Sedangkan penduduk yang bekerja semakin berkurang dari tahun 2012-2016.

Saat ini jumlah angkatan kerja mencapai17,31juta orang bertambah sebesar 14 ribu orang dibanding keadaan Agustus 2015 dan berkurang sebesar 602 ribu orang dibanding keadaan Februari 2016. Penduduk yang bekerja pada agustus 2016 naik sebesar 76 ribu orang dibanding keadaan Agustus 2015, dan berkurang 65 ribu orang dibanding keadaan Februari $2016 "$ (https://klatenkab.bps.go.id).

Banyaknya pengangguran menjadi masalah serius yang dihadapi oleh Indonesia terutama Kabupaten Klaten. Pengangguran bisa disebabkan karena tawaran atau permintaan instansi tidak sesuai dengan ketrampilan yang dimiliki oleh calon tenaga kerja. Dengan demikian dalam menyesuaikan dan memenuhi syarat tersebut butuh adanya program pelatihan ketrampilan.

Berdasarkan Peraturan Menteri

Pendidikan dan Kebudayaan Republik
Indonesia Nomor 81 Tahun 2013 bahwa pendidikan ketrampilan kerja adalah program pendidikan nonformal yang diselenggarakan bagi masyarakat yang memerlukan bekal pengetahuan, ketrampilan, kecakapan hidup, dan sikap untuk mengembangkan diri, mengembangkan profesi, bekerja, dan/atau usaha mandiri untuk meningkatkan kemampuan peserta didik dengan penekanan pada penguasaan ketrampilan fungsional yang sesuai dengan kebutuhan dunia kerja. Bahwa Perkembangan teknologi informasi dan kom unikasi (TIK) telah membawa perubahan ba gi masyarakat Indonesia, dengan TIK masyarakat juga lebih mudah mengakses berbagai informasi dan menunjang pekerjaan. Dunia kerja saat ini membutuhkan tenaga kerja yang terampil dengan cara manual namun juga terampil menggunakan komputer. Maka dalam hal teresbut, mampu diatasi dengan pemberian ketrampilan untuk mengurangi jumlah pengangguran yaitu melalui program kursus komputer.

LKP belum sepenuhnya mengurangi angka pengangguran. maka dari itu diperlukannya peninjauan terhadap pelaksanaan program, apakah sudah sesuai dengan tujuan yang sebelumnya telah dibuat. Hal tersebut, untuk mengetahui efektifitas dari tujuan yang telah ditetapkan dalam program maka diperlukannya evaluasi terhadap program yang telah diselenggarakan. Evaluasi adalah sebuah kegiatan pengumpulan data atau informasi, untuk dibandingkan dengan kriteria, 


\section{Diklus: Jurnal Pendidikan Luar Sekolah, 2(1), Maret 2018 - 55 \\ Widya Eka Wahyu Lestari}

kemudian diambil kesimpulan, (Suharsimi Arikunto, 2007).

\section{METODE PENELITIAN}

\section{Jenis Penelitian}

Penelitian ini merupakan penelitian evaluasi dengan menggunakan pendekatan kualitatif

\section{Waktu dan Tempat Penelitian}

Penelitian ini dilaksanakan di LKP Bimantara Klaten Jl. Kopral Sayom No. 59 Klaten, Dilakukan pada bulan April 2017 - Juni 2017

\section{Target/Subjek Penelitian}

Subjek penelitian yang bertindak memberikan informasi dalam penelitian ini antara lain:

1. Pengelola LKP Bimantara dengan inisial LZ

2. Pelatih kursus office terpadu dengan inisial YNT dan AFF

3. Peserta Pelatihan dengan inisial AL, RT, BSW, DW, dan BR

\section{Prosedur}

Jenis penelitian ini adalah kualitatif jenis deskriptif. Semua data diperoleh melalui metode wawancara, observasi, dan studi dokumentasi. .

Data, Intrumen, dan Teknik Pengumpulan Data

Sumber data yang dipergunakan adalah data primer yang diperoleh melalui wawancara dan observasi di LKP Bimantara Klaten. Selain itu sumber data sekunder diperoleh melalui internet, dan brosur. Instrumen penelitian adalah peneliti sendiri dibantu dengan pedoman wawancara. Peneliti sebagai human instrumen berfungsi menetapkan fokus penelitian memilih subyek penelitian sebagai sumber data, melakukan pengumpulan data, menilai kualitas data dan membuat kesimpulan atas beberapa temuan.

\section{Teknik Analisis Data}

Teknik analisis data yang digunakan meliputi 3 tahap, yaitu reduksi data (penyederhanaan), display data (disajikan), dan penarikan kesimpulan. Keabsahan data yang digunakan adalah menggunakan teknik triangulasi sumber.

\section{HASIL PENELITIAN DAN \\ PEMBAHASAN}

\section{Kebermanfaatan Program Office}

\section{1) Reaksi}

a. Motivasi

Peserta pelatihan yang mengikuti pembelajaran dalam kursus ini juga memiliki suatu dorongan yang membuat mereka lebih bersemangat dan tergerak untuk mengikuti pembelajaran. Proses belajar mengajar orang dewasa adalah suatu proses berlangsungnya kegiatan belajar yang dilakukan oleh peserta didik dan kegiatan mengajar yang dilakukan oleh pendidik atau pembimbing (Suprijanto, 2005 : 39-51).

Adapun orang dewasa cara belajarnya berbeda dengan anak-anak, tidak lain halnya juga dalam motivasinya untuk belajar. Motivasi merupakan hal yang mendorong seseorang dalam melakukan sesuatu untuk mencapai tujuan tertentu. Dari pernyataan 


\section{Diklus: Jurnal Pendidikan Luar Sekolah, 2(1), Maret 2018 - 56 \\ Widya Eka Wahyu Lestari}

peserta pelatihan tentang motivasi mengikuti program kursus diikuti oleh pelatih yang mengatakan bahwa mayoritas karena mungkin saat ini susahnya mencari pekerjaan dengan tingkat pendidikan yang rendah atau hanya lulusan SMP/SMA. Maka dari beberapa ungkapan peserta pelatihan pernyataan tersebut juga diungkapkan oleh pegelola dan peserta pelatihan dan dapat disimpulkan bahwa motivasi dari peserta pelatihan mayoritas adalah motivasi yang baik, motivasi yang berasal dari dalam diri peserta kursus masingmasing. karena peserta pelatihan memiliki motivasi untuk tujuan yang baik, yang nantinya bisa dijadikan bekal dalam dunia pekerjaan dan pengalaman dalam kehidupannya.

b) Harapan

Harapan adalah kepercayaan akan sesuatu yang diinginkan atau didapatkan, bentuk harapan tersebut bersifat abstrak. Peserta pelatihan yang mengikuti pembelajaran dalam kursus ini memiliki harapan agar terwujud apa yang diinginkan nantinya setelah mengikuti kursus ini. harapan peserta pelatihan dalam mengikuti kursus office ini dapat dikatakan baik. Peserta pelatihan memiliki harapan yang baik dalam jenjang karier mereka setelah mengikuti kursus.

c) Kualitas Pengajar

Kualitas pengajar merupakan salah satu aspek yang akan dievaluasi. Pengajar/pelatih adalah pendidik profesional yang memiliki tugas utama membimbing, memotivasi, dan memfasilitasi belajar peserta didik pada jalur pendidikan nonformal. Dalam proses pembelajaran pelatih juga memberikan motivasi agar peserta pelatihan untuk terus belajar. Adapun teori yang kurang dipahami oleh peserta/warga belajar untuk dipraktikan pelatih siap sedia untuk menjelaskan kembali supaya peserta mampu memahami. Dari data tersebut dapat dimaknai bahwa kualitas pengajar yang sudah cukup baik membantu peserta pelatihan dalam mengikuti pembelajaran program office terpadu.

d) Fasilitas yang disediakan

Fasilitas yang disedikan oleh LKP Bimantara cukup nyaman peserta pelatihan masing-masing bisa menggunakan satu komputer untuk praktek, pemberian modul dan materi, ruangan yang bersihn sehingga peserta pelatihan mau belajar, berlatih dan mau mengikuti proses yang ada. Namun jumlah komputer yang disediakan terbatas, maka LKP mneggunakan penjadwalan untuk sesi 1, 2, 3 dan 4 .

Hasil evaluasi reaksi, program kursus office terpadu yang diselenggarakan oleh LKP Bimantara sudah termasuk dalam kepuasan peserta pelatiahn/warga belajar, pogram yang diselenggrakan selaras dengan motivasi peserta pelatihan/warga belajar. Kepuasan peserta pelatihan dapat dikaji dari beberapa aspek yaitu motivasi, harapan, fasilitas yang disediakan dan kualitas pengajar.

\section{2) Belajar}

Evaluasi belajar dilakukan untuk mengetahui sejauh mana daya serap peserta pelatihan terhadap materi yang diberikan 


\section{Diklus: Jurnal Pendidikan Luar Sekolah, 2(1), Maret 2018 - 57 \\ Widya Eka Wahyu Lestari}

dalam program serta mengetahui peningkatan pengetahuan dan skill yang diperoleh dari program. adapun aspek nya meliputi :

a) Aktivitas peserta pelatihan

Dalam pembelajaran office terpadu peserta pelatihan tidak hanya diam saja. mencermati yang disampaikan oleh pelatih, dan jika ada yang kurang dipahami peserta pelatihan langsung menanyakan kepada pelatih.

b) Aktivitas pelatih

Pelatih/tutor menjelaskan materi lalu mempraktikan, pelatih didalam proses pembelajaran tidak hanya diam, tetapi juga mengamati apa yang sedang dikerjakan peserta. Menurut Ikka Kartika (2011 : 104) menyebutkan bahwa pelatih/ instruktur/ tutor adalah seseorang yang melayani dan memperlancar aktivitas belajar peserta pelatihan untuk mencapai tujuan berdasarkan pengalaman. Pelatih/tutor menguasai materi dimulai dari menyalakan komputer sampai mengolah data, tidak hanya itu tutor/pelatih juga memberikan motivasi dan semangat kepada peserta pelatihan/warga belajar agar merasa nyaman berada dalam proses pembelajaran. bahwa aktivitas pelatih sudah dikatakan baik karena tidak hanya sekedar memberikan teori materi saja, namun memberikan dukungan berupa motivasi agar terus belajar dan berusaha.

c) Strategi pembelajaran

$$
\text { Strategi pembelajaran }
$$

merupakan cara yang dilakukan oleh pelatih/tutor agar pembelajaran dapat berlangsung secara efektif. strategi pembelajaran yang dilakukan oleh LKP Bimantara yaitu dengan pemberian teori dan praktek kepada peserta pelatihan, sehingga peserta pelatihan mampu menyerap materi yang diberikan oleh pelatih.

d) Kurikulum

Kurikulum merupakan pedoman yang digunakan didalam sebuah program, agar program yang diselenggarakan dapat terarah dan dapat mencapai tujuan yang telah ditetapkan. Kurikulum yng digunakan didalam program kursus disesuaikan dengan kurikulum nasional dari pusat tentang komputer.

e) Materi pelatihan

Materi yang digunakan dalam program microsoft office adalah microsoft word, microsoft excel, microsoft powerpoint.i LKP Bimantara juga mengacu dan menyesuiakan dengan kurikulum nasional. Kurikulum yanga ada sebagai acuan LKP Bimantara dalam membuat modul.

f) Jadwal pembelajaran

Guna berjalannya program LKP Bimantara memberikan jadwal terkait pelkasanaan program kursus office terpadu. Adapun jadwal pembelajaran yang disediakan bertujuan agar proses pembelajaran berjalan dengan tertib 


\section{Diklus: Jurnal Pendidikan Luar Sekolah, 2(1), Maret 2018 - 58 \\ Widya Eka Wahyu Lestari}

dan rapi. LKP Bimantara untuk program office terpadu ada 4 sesi, yaitu sesi pertama untuk pukul 8 sampai jam 10, lalu sesi kedua pukul 10.30 sampai 12.30, lalu sesi ketiga pukul 13. 00 sampai 15.00. Setelah adanya penjadwalan, LKP Bimantara memberikan jeda 30 menit dilakukan istirahat, setelah itu dilaksanakan kembali oleh peserta yang lain. Namun berjalannya waktu, waktu pembelajaran disesuaikan dengan kebutuhan warga belajar dan kesesuaian waktu luang mereka

Evaluasi belajar adalah terjadinya perubahan sikap, pengetahuan, dan ketrampilan peserta pelatihan setelah mengikuti program. rata-rata dari mereka sebagaian adalah pekerja, maka waktu pembelajaran juga menyesuaikan peserta pelatihan, dengan tutor yang memiliki latar belakang pendidikan yang sesuai dengan program. Sehingga diperkaya pengetahuan dan pengusaan materi. Kurikulum yang digunakan LKP Bimatara menyesuaiakan kurikukulm nasional. Program yang diikuti juga telah sesuai dengan keinginan dan kebutuhan peserta pelatihan.

\section{3) Perilaku}

Pada tahap ini difokuskan pada perubahan perilaku, yaitu meliputi partisipasi peserta pelatihan dan ketercapaian tujuan. a. Partisipasi Peserta Pelatihan peserta pelatihan tetap hadir dalam proses pembelajaran, dan mengikuti pembelajaran dengan baik, peserta pelatihan menyimak dan memeperhatikan apa yang dijelaskan oleh pelatih/tutor.

b. Ketercapaian Tujuan

Diadakannya program office terpadu adalah untuk memenuhi kebutuhan dari warga belajar/peserta pelatihan, serta membekali juga kepada peserta pelatihan/warga belajar agar memiliki skill tambahan. Tujuan peserta pelatihan sendiri adalah untuk menambah ilmu, menambah pengalaman, dan menambah ketrampilan dalam bidang komputer khususnya microsoft office.

Dapat dimaknai dalam ketercapaian dari aspek koginitif adalah peserta pelatihan mendapat ilmu baru, dari aspek afektif bertambahnya ketrampilan peserta pelatihan dalam mengikuti program office terpadu dan dari aspek psikomotorik peserta pelatihan mampu mengaplikasikan ilmu dan ketrampilannya dalam kehidupan sehari-hari ataupun dalam dunia kerja. Pada terjadi perubahan sikap pada saat kegiatan pelatihan yang bersifat internal. Peserta pelatihan dapat dikatakan telah belajar dan telah mengalami perubahan sikap, pengetahuan, dan ketrampilan. 


\section{Diklus: Jurnal Pendidikan Luar Sekolah, 2(1), Maret 2018 - 59 \\ Widya Eka Wahyu Lestari}

\section{4) Hasil}

Menghasilkan peserta pelatihan yang lebih terampil dan dapat menguasai keterampilan sesuai dengan tingkatan kursus yaitu dalam microsoft office.

Peserta pelatihan menjadi lebih percaya diri dan semakin yakin dengan ketrampilan yang mereka miliki untuk mendapat pekerjaan. Maka dampak dari program yang telah dilaksanakan adalah peserta pelatihan menjadi lebih bisa menggunakan komputer dan sistem microsoft office, mereka juga bisa lebih percaya diri dengan bekal ketrampilan yang dimiliki.

\section{Faktor Pendukung}

Faktor pendukung sangat berpengaruh dalam terlaksananya pendidikan dan pelatihan.

\section{a) Sarana Prasarana}

Berdasarkan kondisi sarana dan prasarana yang ada di LKP Bimantara, komputer yang cukup masih baik dan bisa dipergunakan. Karena setiap 1-2 bulan sekali komputer dibersihkan dan dicek oleh pengelola dan saran yang yang lain untuk dilakukn perawatan. Dalam program LKP Bimantara sarana dan prasarana program pembelajaran office terpadu adalah komputer, ruangan, meja, kursi, alat tulis. Hal ini berdasar pada penggunaaa sarana dan prasarana dalam program office terpadu. Sarana dan prasarana yang digunakan mendukung proses pembelajaran dan sarana prasarana yang tersedia mencukupi kebutuhan pembelajaran.

\section{b) Pembiayaan}

Pendanaan dalam program berasal dari dana masing-masing peserta pelatihan dan lembaga yang kemudian dikelola demi mencukupi kebutuhan dalam keberlangsungan program pelatihan microosft office di LKP Bimantara. sehingga dana yang dikelola berjalan dengan baik. dana yang dikelola oleh pengelola berjalan dengan baik dan selalu terbuka kepada peserta pelatihan, sehingga penggunaan biaya dari peserta digunakan sesuai kebutuhan peserta pelatihan. Dapat dimaknai bahwa biaya yang digunakan sudah sesuai dengan apa yang dibutuhkan dalam pelaksanaan program.

\section{SIMPULAN DAN SARAN}

\section{Simpulan}

Berdasarkan uraian hasil penelitian dan pembahasan mengenai kebermanfaatan program kursus office terpadu di LKP Bimantara Klaten dapat diambil kesimpulan sebagai berikut:

1. Berdasarkan evaluasi reaksi, program kursus office terpadu yang diselenggarakan oleh LKP Bimantara sudah termasuk dalam kepuasan peserta pelatiahn/warga belajar, pogram yang diselenggrakan selaras dengan motivasi peserta pelatihan/warga belajar. Kepuasan peserta pelatihan dapat dikaji dari beberapa aspek yaitu motivasi, harapan, 


\section{Diklus: Jurnal Pendidikan Luar Sekolah, 2(1), Maret 2018 - 60 \\ Widya Eka Wahyu Lestari}

fasilitas yang disediakan dan kualitas pengajar.

Bedasarkan evaluasi belajar, terjadinya perubahan sikap, pengetahuan, dan ketrampilan peserta pelatihan setelah mengikuti program. rata-rata dari mereka sebagaian adalah pekerja, maka waktu pembelajaran juga menyesuaikan peserta pelatihan, dengan tutor yang memiliki latar belakang pendidikan yang sesuai dengan program. Sehingga diperkaya pengetahuan dan pengusaan materi. Kurikulum yang digunakan LKP Bimatara menyesuaiakan kurikukulm nasional. Program yang diikuti juga telah sesuai dengan keinginan dan kebutuhan peserta pelatihan.

Berdasarkan evaluasi perilaku, partisipasi peserta pelatihan sudah cukup baik, sehingga tujuan tercapai, yaitu terjadinya perubahan sikap, ilmu dan pengalaman baru bagi peserta pelatihan. tujuan yang rencanakan oleh lembaga sejalan dengan tujuan dari peserta pelatihan.

Berdasarkan evaluasi hasil, program kursus office terpaud di LKP Bimantara telah dapat mencapai tujuan yang telah ditentukan LKP Bimantara yang telah membekali ketrampilan yang nantinya sebagai bekal didunia kerja. Hasil yang diperoleh warga belajaradalah memiliki kemampuan menggunakan microsoft office. Dampak program ini adalah warg belajar lebih percaya diri, lebih yakin dengan kemampuan yang mereka milik.
2. Berdasarkan faktor pendukung, pendanaan dalam program kursus menjahit di LKP Bimantara berasal dari dana peserta pelatihan dan dana pemerintah yang diajukan oleh lembaga. Sarana dan prasarana yang ada di Bimantara sudah dapat menunjang proses pembelajaran. Rutin diadakan perawatan untuk mesin yang digunakan dalam pembelajaran. Tetapi dari segi ruang masih kurang memadai dan kurang luas, karena bangunan yang digunakan masih menjadi satu dengan rumah dan toko alat komputer.

\section{Saran}

Berdasarkan hasil penelitian yang telah diperoleh, peneliti memiliki beberapa saran :

1. Tujuan yang diselenggarakan telah selaras dengan kebutuhan warga belajar., LKP Bimantara harus mempertahankannya agar tujuan bisa selaras dengan kebutuahn warga belajar.

2. Kinerja tutor harus dipertahankan, agar tetap membeikan pengajaran yang terbaik pada peserta pelatihan guna mencetak warga belajar yang memiliki kemampuan dalam bidang office dan memiliki daya saing.

3. Sumber daya manusia, pendanaa, sarana prasarana yang ada harus tetap dipertahanklan kualitasnya. LKP Bimantara bisa tetap memberikan pelayan terbaik kepada peserta pelatihan. lakukan 


\section{Diklus: Jurnal Pendidikan Luar Sekolah, 2(1), Maret 2018 - 61 \\ Widya Eka Wahyu Lestari}

kerjasama dengan instansi lain untuk

menambah biaya penyelenggaraan.

Program office tepadu yang diselenggarakan

oleh LKP Bimantara harus tetap

dipertahankan. Kerjasama yang baik anatar

pengelola, pelatih dan warga belajar maupun

pihak lain harus dapat dipertahankan dengan

baik. Agar kebutuhan warag belajar yang

mengikuti program memiliki kulaitas yang

mampu mencetak lulusan yang baik

\section{DAFTAR PUSTAKA}

Suprijanto. (2005). Pendidikan Orang Dewasa. Jakarta : PT Bumi Aksara

Badan Pusat Statistik Kabupaten Klaten. Diakses dari https://klatenkab.bps.go.id Selasa,23 November 2016. Pukul 16.04 WIB

Arikunto, Suharsimi \& Cepi Safrudin. (2007) . Evaluasi Program Pendidikan Pedoman Teoritis Praktis Bagi Praktisi Pendidikan. Jakarta : PT Bumi Aksara.

Kamil, Mustofa. (2010). Model Pendidikan dan Pelatihan. Bandung : Alfabeta

Kartika, Ikka A. Fauzi (2014). Mengelola Pelatihan Partisipatif. Bandung:

Alfabeta

Samsul Hadi. (2012). Evaluasi Implementasi Kurikulum Berbasis Kompetensi pada Lembaga Kursus dan Pelatihan (LKP) Program Otomotif. Jurnal Pendidikan Vokasi, Vol 2, No.3. Hal 268. 